\title{
Purification of Food-grade Magnesium Chloride
}

\author{
Lianmin $\mathrm{Ji}^{1}$, Zhiqi Liu ${ }^{1}$ a, Lijuan $\mathrm{Li}^{1}$, Xuexue Song ${ }^{1}$, Zhongmin Zeng ${ }^{1}$, Feng $\mathrm{Nie}^{1}$ \\ ${ }^{1}$ Key Laboratory of Comprehensive and Highly Efficient Utilization of Salt Lake Resources, Chinese Academy of Sciences \\ Qinghai Institute of Salt Lakes, Chinese Academy of Sciences, 810008 Xining Qinghai, China
}

\begin{abstract}
The application of the varying weights of bischofite dissolved in the distilled water was investigated. The effects of the temperature on the rate of evaporation and the thermal precipitation time on the purity of the crystal products were fully investigated. Two validation tests including magnifying tests and recycling residue were also studied. Our results demonstrate that the contents of $\mathrm{NaCl} 、 \mathrm{KCl}$ and $\mathrm{CaSO}_{4}$ in the filtrate reached a minimum value after the pretreatment of $350 \mathrm{~g}$ bischofite dissolved in $100 \mathrm{ml}$ distilled water. In the crystal products from the second evaporating stage of the validation tests, the contents of $\mathrm{MgCl}_{2} \cdot 6 \mathrm{H}_{2} \mathrm{O}, \mathrm{SO}_{4}$ and $\mathrm{NaCl}+\mathrm{KCl}$ are $99 \%, \leq 0.1 \pm 0.01 \%$ and $\leq 0.8 \pm 0.04 \%$, respectively. The content of magnesium chloride in the solution was increased to a greater extent, and the impurities reduced correspondingly through the dissolution pretreatments of bischofite. This could decrease energy consumption for the impurity removing stage, evaporation and crystallization process, and thus reduce costs for the industrial production of food-grade magnesium chloride
\end{abstract}

\section{Introduction}

The positive correlation between diet and health has led health agencies around the world to control the intake of certain food components that are thought to promote some disorders [1].According to the national standards for food safety (GB2760-1996-2005), the additives used in food production must be food grade additives. Edible magnesium chloride $\left(\mathrm{MgCl}_{2} \cdot 6 \mathrm{H}_{2} \mathrm{O}\right)$ as additive has more widely application in food, salt, mineral water, medicine and other industries [1-4].

The Qinghai salt lakes in the qaidam basin are well known for their huge reserves of potassium chloride $(\mathrm{KCl})$ and magnesium chloride $\left(\mathrm{MgCl}_{2}\right)$ in China [5]. In recent years, about $4.5 \mathrm{Mt} \cdot \mathrm{a}^{-1}$ potassium fertilizer has been produced with 24-30 $\mathrm{Mt} \cdot \mathrm{a}^{-1}$ magnesium chloride as by-product, and a large amount of magnesium chloride has been left as the by-product or even waste in salt lakes of Qinghai [6,7]. This has caused not only the waste of magnesium resources, but also the environmental pollution [8]. The production of food grade magnesium chloride used bischofite as raw material is another effective utilization way of magnesium resources of salt lake, in which it is playing an active role.

This study investigated the performance of the varying weights of bischofite dissolved in the distilled water, determined the optimal ratio relationship between bischofite and distilled water under the condition of the least amount of impurity in the filtrate, and confirmed the reliability and repeatability of the optimal dissolution ratio.

\section{Experimental}

\subsection{Reagents and instrumentation}

The raw ore used in this study included bischofite (Golmud zhenghai magnesium science and technology development Co., Ltd.)

The instruments used for the analyses included stirrer (IKA EUROSTAR 60; Shanghai Chuangyi Science and education equipment Co., Ltd.), oil bath pan (DF-101S; Gongyi Yuhua Instrument Co., Ltd.), an inductively coupled plasma-atomic emission spectrometer (ICAP6500 DUO; America Thermo Scientific, USA).

\subsection{Experiments}

\subsubsection{Solution analysis}

The solution with a certain amount of bischofite dissolved in the distilled water was mechanically stirred at a frequency of $300 \mathrm{rpm}$ for $30 \mathrm{~min}$ at room temperature (20 $\pm 2{ }^{\circ} \mathrm{C}$ ). Subsequently, the residue and filtrate were separated and weighed. The filtrate was analyzed using EDTA volumetric analysis to determine the $\mathrm{Mg}^{2+}, \mathrm{Cl}^{-}$ concentrations, and inductively coupled plasma-atomic emission spectrometry (ICP) to determine the $\mathrm{Na}^{+}, \mathrm{K}^{+}$, $\mathrm{Ca}^{2+}, \mathrm{As}, \mathrm{Pb}, \mathrm{SO}_{4}{ }^{2-}$ and $\mathrm{B}_{2} \mathrm{O}_{3}$.

\subsubsection{Evaporative crystallization}

\footnotetext{
$\overline{{ }^{a} \text { Corresponding author: zqliu@isl.ac.cn }}$
} 
(1) First evaporating stage

The filtrate was heated up to $110 \pm 5{ }^{\circ} \mathrm{C}$ for some water loss, and then thermally precipitated for $1 \mathrm{~h}$, finally, conducted with thermal filtration.

(2) Second evaporating stage

In order to obtain crystals $\mathrm{MgCl}_{2} \cdot 6 \mathrm{H}_{2} \mathrm{O}$, this filtrate from the first evaporating stage was heated up to $140{ }^{\circ} \mathrm{C}$ again for some water loss, and then the thermal refrigerated to $40{ }^{\circ} \mathrm{C}$ for filtration. Finally, the product of crystals $\mathrm{MgCl}_{2} \cdot 6 \mathrm{H}_{2} \mathrm{O}$ was obtained and analyzed using EDTA volumetric analysis to determine the $\mathrm{Mg}^{2+}$ concentrations, and ICP to determine the $\mathrm{Na}^{+}, \mathrm{K}^{+}, \mathrm{Ca}^{2+}$ and $\mathrm{SO}_{4}{ }^{2-}$ concentrations.

The process flowsheet for purification of food-grade magnesium chloride was shown in Figure 1.

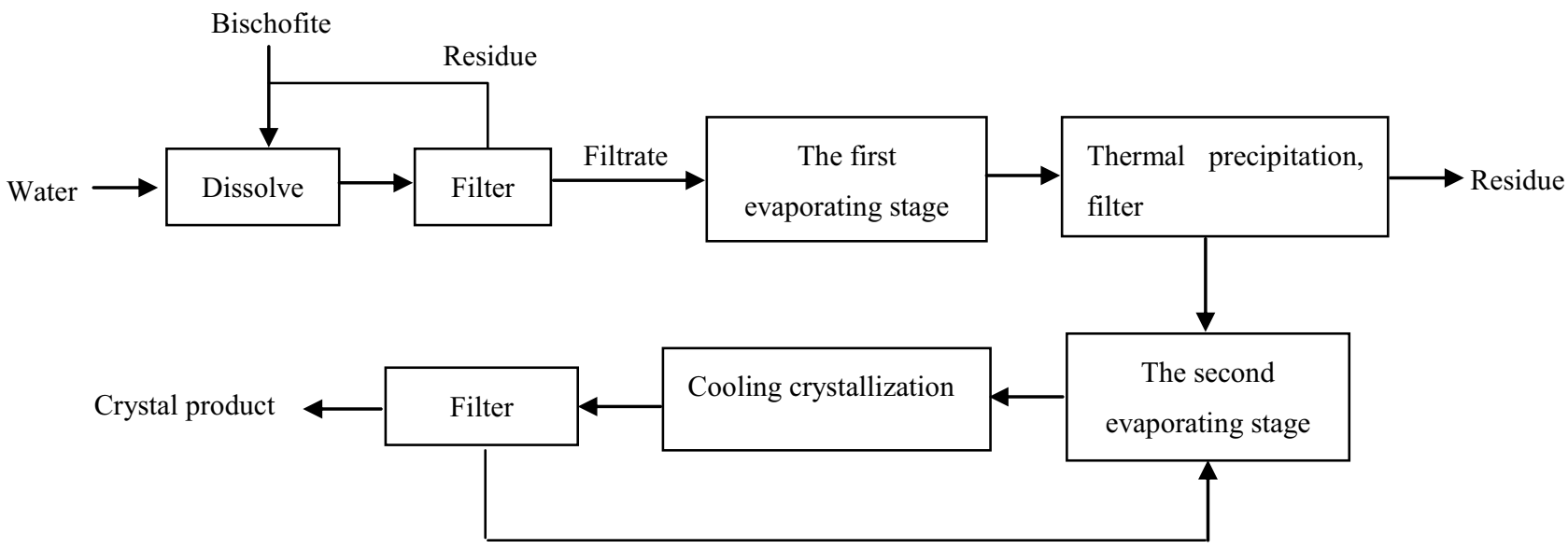

Figure 1. Process flowsheet for purification of food-grade magnesium chloride

\section{Results and Discussion}

\subsection{Materials analysis}

In order to obtain the composition of the bischofite, the solution with $50.0390 \mathrm{~g}$ bischofite dissolved in the distilled water was transferred into a $500 \mathrm{ml}$ volumetric flask, and then analyzed using EDTA volumetric analysis and ICP. The result of such analysis is presented in table 1. The original magnesium chloride content (wt. \%) is $44.77 \%$. The contents of impurities $\mathrm{As}, \mathrm{B}_{2} \mathrm{O}_{3}$ and $\mathrm{Pb}$ in bischofite are unavailable due to extremely low values. The total contents of insoluble matter and soluble impurities $\left(\mathrm{NaCl}+\mathrm{KCl}+\mathrm{CaSO}_{4}\right)($ wt. \%) are $<0.10 \%$ and $4.6 \%$, respectively.

Table 1. Result of materials analysis

\begin{tabular}{|c|c|}
\hline Constitutes & Content (wt. \%) \\
\hline $\mathrm{As}$ & 0.00006595 \\
\hline $\mathrm{B}_{2} \mathrm{O}_{3}$ & 0.0003732 \\
\hline $\mathrm{Ca}^{2+}$ & 0.2314 \\
\hline $\mathrm{K}^{+}$ & 0.8693 \\
\hline $\mathrm{Na}^{+}$ & 0.8469 \\
\hline $\mathrm{Pb}$ & 0.00002598 \\
\hline $\mathrm{SO}_{4}{ }^{2-}$ & 0.5372 \\
\hline $\mathrm{MgCl}_{2}$ & 44.77 \\
\hline $\mathrm{NaCl}$ & 2.15 \\
\hline $\mathrm{KCl}$ & 1.66 \\
\hline $\mathrm{CaSO}_{4}$ & 0.79 \\
\hline Insoluble matter & 0.095 \\
\hline
\end{tabular}

\subsection{Varying solubility experiment}

The experiments were conducted to investigate the effect of the solubility of bischofite on the contents of soluble impurities in the filtrate. The bischofites with weights varying from $100 \mathrm{~g}$ to $500 \mathrm{~g}$ were dissolved in the distilled water of $100 \mathrm{ml}$. After filtering, the density of filtrate, the concentrations of $\mathrm{MgCl}_{2}$ and the components of soluble impurities were analyzed respectively.

As is shown in Figure 2, the contents of residue gradually increased with increasing the weights of bischofite. The contents increased rapidly with bischofite weights higher than $350 \mathrm{~g}$. Notably, a large amounts of mineral $\mathrm{MgCl}_{2} \cdot 6 \mathrm{H}_{2} \mathrm{O}$ dissolved and remained in the residue. As observed in the Figures 2 and 3, the weight contents of $\mathrm{MgCl}_{2}$ steadily increased with increasing bischofite weight. However, the contents of $\mathrm{NaCl}$ and $\mathrm{KCl}$ initially increased and then rapidly decreased with increasing bischofite weights. While the $\mathrm{CaSO}_{4}$ contents declined straightly. When the bischofite weight was higher than $350 \mathrm{~g}$, all the $\mathrm{NaCl}, \mathrm{KCl}$ and $\mathrm{CaSO}_{4}$ contents reached minimum levels. Therefore, the relationship of optimal ratio between bischofite and distilled water was determined as $350 \mathrm{~g} / 100 \mathrm{ml}$.

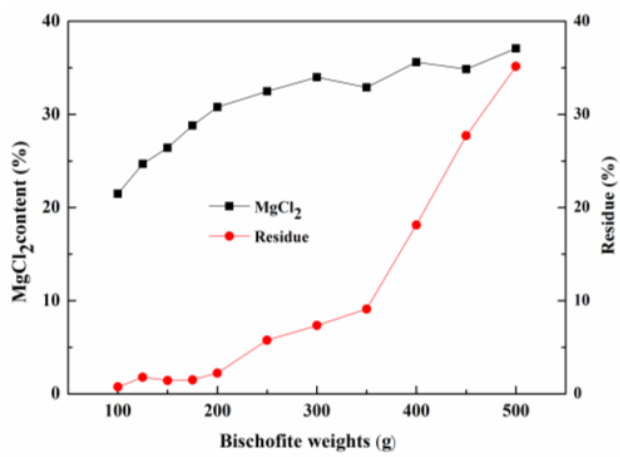

Figure 2. Relationship between $\mathrm{MgCl}_{2}$ and residue with bischofite dissolved in the distilled water of $100 \mathrm{ml}$ 


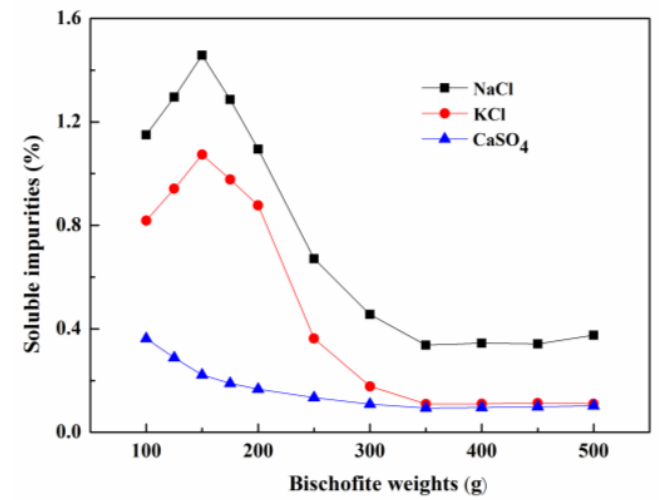

Figure 3. Relationship between soluble impurities with bischofite dissolved in the distilled water of $100 \mathrm{ml}$

\subsection{Effect of temperature}

To confirm the temperature for the second evaporating stage, the studies were carried out through varying temperature from 140 to $170{ }^{\circ} \mathrm{C}$ for $240 \mathrm{~min}$. The results are shown in Figure $4 \mathrm{a}$ and $\mathrm{b}$. The evaporative loss of water initially decreased sharply and then gently declined with lengthening time.

The average speeds of evaporation during the time of $0 \sim 75 \mathrm{~min}$ were $0.46,0.49,0.53$ and $0.55 \mathrm{~g} / \mathrm{min}$, respectively. While the average speeds during the time of $75 \sim 240 \mathrm{~min}$ were $0.051,0.054,0.063$ and $0.053 \mathrm{~g} / \mathrm{min}$ respectively. As observed, all the evaporation rates became slow after $75 \mathrm{~min}$, and had nothing to do with the temperature. Therefore, the optimal evaporation temperature was $140{ }^{\circ} \mathrm{C}$ for the purpose of reducing energy consumption.
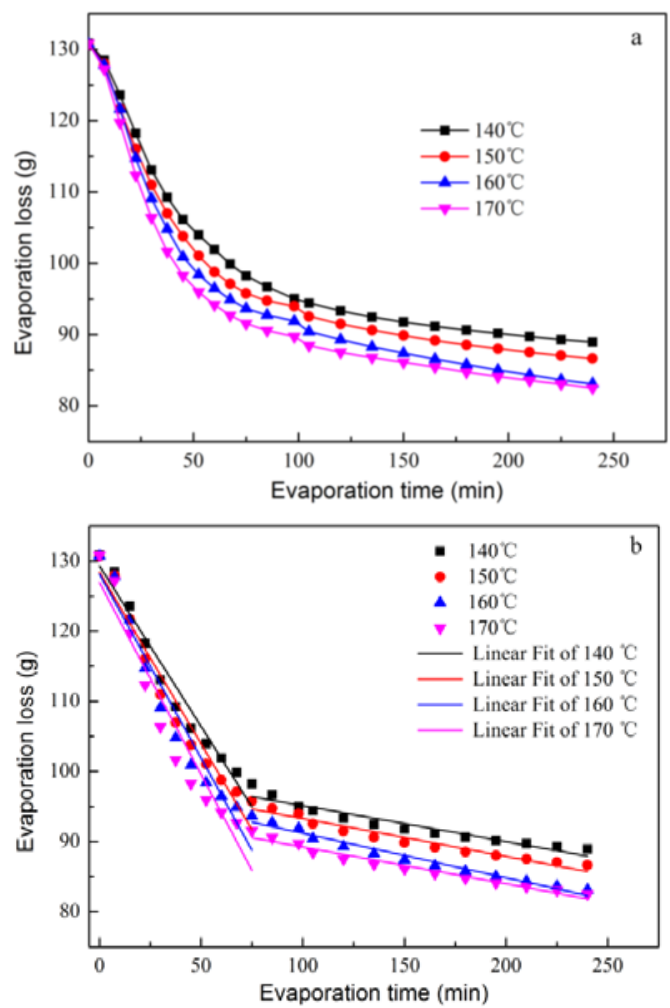

Figure 4. Effect of the temperature on the evaporation rate (a and b)

\subsection{Effect of the thermal precipitation time}

According to the optimal ratio of $350 \mathrm{~g}$ bischofite to 100 $\mathrm{ml}$ distilled water, the filtrate was obtained and heated up to $110 \pm 5{ }^{\circ} \mathrm{C}$ for some water loss, and then thermally precipitated for $1 \sim 5 \mathrm{~h}$. Finally, it was conducted with filtration. The result for the effect of the thermal precipitation time on the purity of crystal product is listed in the Table 2. Table 2 shows that the purities of crystal product reached maximum levels when the thermal precipitation time was $1-3 \mathrm{~h}$. However, the purity value reduced as the thermal precipitation time was $5 \mathrm{~h}$. Based on the energy consumption consideration, the optimum time is $1 \mathrm{~h}$.

Table 2. Effect of the thermal precipitation time

\begin{tabular}{|c|c|}
\hline Precipitation time (h) & $\left.\mathbf{M g C l}_{\mathbf{2}} \mathbf{( w t .} \mathbf{\%}\right)$ \\
\hline 1 & 46.30 \\
\hline 2 & 46.18 \\
\hline 3 & 46.39 \\
\hline 5 & 45.37 \\
\hline Precipitation time (h) & $\mathbf{M g C l}_{\mathbf{2}} \mathbf{6} \mathbf{H}_{\mathbf{2}} \mathbf{O}$ (wt. \%) \\
\hline 1 & 98.86 \\
\hline 2 & 98.61 \\
\hline 3 & 99.06 \\
\hline 5 & 96.88 \\
\hline
\end{tabular}

\subsection{Validation}

\subsubsection{Magnifying tests}

The solutions were obtained with $1750 \mathrm{~g}$ bischofite dissolved in $500 \mathrm{ml}$ distilled water, 5 times the original weights based on the optimal ratio in the section 3.2 , and conducted to the first and second evaporating stages after filtration. The analyzed results of the products are shown in the tables 3 and 4 . In those two products, the varying evaporation losses (17.32 $\mathrm{g}$ and $16.25 \mathrm{~g}$ ) for the first stage gave rise to the different weight levels of crystals $(12.68 \mathrm{~g}$ and $3.63 \mathrm{~g}$, respectively) (Table 3). However, the total contents of $\mathrm{MgCl}_{2} \cdot 6 \mathrm{H}_{2} \mathrm{O}, \mathrm{SO}_{4}$ and $\mathrm{NaCl}+\mathrm{KCl} \quad$ (wt. \%) were $>99 \%,<0.1 \%$ and $<0.6 \%$, respectively (Table 4). This reveals that the varying evaporation losses for the first stage have no influence on the contents of the crystal products for the second stage.

Table 3. Weights of evaporation loss and crystal

\begin{tabular}{|c|c|}
\hline Test 1 stages & g \\
\hline Evaporation loss for the first stage & 17.32 \\
\hline Crystal for the first stage & 12.68 \\
\hline Evaporation loss for the second stage & 45.65 \\
\hline Crystal for the second stage & 194.79 \\
\hline Test 2 stages & $\mathbf{g}$ \\
\hline Evaporation loss for the first stage & 16.25 \\
\hline Crystal for the first stage & 3.63 \\
\hline Evaporation loss for the second stage & 45.34 \\
\hline Crystal for the second stage & 203.84 \\
\hline
\end{tabular}


Table 4. Contents of crystal products for the second stage

\begin{tabular}{|c|c|}
\hline Product 1 & wt. \% \\
\hline $\mathrm{MgCl}_{2}$ & 46.41 \\
\hline $\mathrm{MgCl}_{2} \cdot 6 \mathrm{H}_{2} \mathrm{O}$ & 99.10 \\
\hline $\mathrm{NaCl}$ & 0.47 \\
\hline $\mathrm{KCl}$ & 0.12 \\
\hline $\mathrm{CaSO}_{4}$ & 0.022 \\
\hline $\mathrm{SO}_{4}$ & 0.015 \\
\hline Product 2 $^{2}$ & wt. \% \\
\hline $\mathrm{MgCl}_{2}$ & 46.47 \\
\hline $\mathrm{MgCl}_{2} \cdot 6 \mathrm{H}_{2} \mathrm{O}$ & 99.23 \\
\hline $\mathrm{NaCl}_{\mathrm{KCl}}$ & 0.46 \\
\hline $\mathrm{CaSO}_{4}$ & 0.12 \\
\hline $\mathrm{SO}_{4}$ & 0.031 \\
\hline & 0.022 \\
\hline
\end{tabular}

\subsubsection{Recycling residue}

(1) The solution with $350 \mathrm{~g}$ bischofite dissolved in the distilled water was mechanically stirred for $30 \mathrm{~min}$, and then filtered.

(2) The residue from the section (1) was weighted and mixed with bischofite into mixture of total $350 \mathrm{~g}$. Then, repeat the operation (1).

(3) Repeat the above (1) and (2) for 2 times. Finally, the obtained filtrate was conducted to the first and second evaporating stages after filtration. The analyzed results of the products are shown in the tables 5 and 6 . In the two products, the varying evaporation losses $(22.87 \mathrm{~g}$ and $29.62 \mathrm{~g}$ ) for the first stage resulted in the crystals $(27.78 \mathrm{~g}$ and $41.92 \mathrm{~g}$, respectively) (Table 5). However, the total contents of $\mathrm{MgCl}_{2} \cdot 6 \mathrm{H}_{2} \mathrm{O}, \mathrm{SO}_{4}$ and $\mathrm{NaCl}+\mathrm{KCl}$ (wt. \%) are $99 \%$ approximately, $\leq 0.1 \pm 0.01 \%$ and $\leq 0.8 \pm 0.04 \%$, respectively (Table 6). This also indicates that the varying evaporation losses for the first stage have no influence on the contents of the crystal products for the second stage.

Table 5. Weights of evaporation loss and crystal

\begin{tabular}{|c|c|}
\hline Test 1 stages & $\mathbf{g}$ \\
\hline Evaporation loss for the first stage & 22.87 \\
\hline Crystal for the first stage & 27.78 \\
\hline Evaporation loss for the second stage & 33.16 \\
\hline Crystal for the second stage & 261.34 \\
\hline Test 2 stages & $\mathbf{g}$ \\
\hline Evaporation loss for the first stage & 29.62 \\
\hline Crystal for the first stage & 41.92 \\
\hline Evaporation loss for the second stage & 30.15 \\
\hline Crystal for the second stage & 240.57 \\
\hline
\end{tabular}

As shown in the validation results for magnifying tests and recycling residue, the products obtained meet the product qualification (GB 25584-2010), according to the optimal ratio relationship between bischofite and distilled water $(350 \mathrm{~g}: 100 \mathrm{ml})$.
Table 6. Contents of crystal products for the second stage

\begin{tabular}{|c|c|}
\hline Product 1 & wt. \% \\
\hline $\mathrm{MgCl}_{2}$ & 46.20 \\
\hline $\mathrm{MgCl}_{2} \cdot 6 \mathrm{H}_{2} \mathrm{O}$ & 98.65 \\
\hline $\mathrm{NaCl}$ & 0.61 \\
\hline $\mathrm{KCl}$ & 0.17 \\
\hline $\mathrm{CaSO}_{4}$ & 0.14 \\
\hline $\mathrm{SO}_{4}$ & 0.099 \\
\hline Product 2 & wt. \% \\
\hline $\mathrm{MgCl}_{2}$ & 46.36 \\
\hline $\mathrm{MgCl}_{2} \cdot 6 \mathrm{H}_{2} \mathrm{O}$ & 98.99 \\
\hline $\mathrm{NaCl}_{\mathrm{KCl}}$ & 0.64 \\
\hline $\mathrm{CaSO}_{4}$ & 0.20 \\
\hline $\mathrm{SO}_{4}$ & 0.16 \\
\hline & 0.11 \\
\hline
\end{tabular}

\section{Conclusions}

(1) The optimal ratio relationship between bischofite and distilled water was $350 \mathrm{~g}: 100 \mathrm{ml}$.

(2) As shown in the validation results for magnifying tests and recycling residue, the products obtained according to the optimal ratio meet the product qualification. In the products, the total contents of $\mathrm{MgCl}_{2} \cdot 6 \mathrm{H}_{2} \mathrm{O}, \mathrm{SO}_{4}$ and $\mathrm{NaCl}+\mathrm{KCl}$ (wt. \%) are $99 \%$ approximately, $\leq 0.1 \pm 0.01 \%$ and $\leq 0.8 \pm 0.04 \%$, respectively.

\section{Acknowledgments}

The authors appreciate the financial support of Key Project supported by QingHai Science Technology Department (2014-GX-C10) and (2015-HZ-812).

\section{References}

1. C. Horita, M. Morgano, R. Celeghini, M. Pollonio, Meat Sci. 89, 426 (2011).

2. W. Q. Yang, Chem. Technol. Market 32, 33 (2009).

3. S. Barbut, C. Findlay, J. Food Sci. 56, 180 (1991).

4. K. Toda, K. Yagasaki, K. Takahashi, Biosci., Biotechnol., Biochem. 72, 2824 (2008).

5. P. Zhang, B. Zhang, Y. Tang, C. Yang, S. Huang, J. Wu, Sci. Press 99, 107 (1999).

6. Y. Zhou, L. J. Li, Z. J. Wu, X. Li, Chem. Res. 25, 1613 (2013).

7. W. T. Cheng, Z. B. Li, G.P. Demopoulos, Chin. J. Chem. Eng. 17, 661 (2009).

8. P. Ma, Adv. Earth. Sci. 15, 365 (2000). 